\title{
Soil pH and Nutrient Characteristics of Newly- added Cultivated Land in Heyang, China
}

\author{
Gang $\mathrm{Li}^{1,2,3,4,5}$, Ruiqing Zhang ${ }^{1,2,3,4,5}$, Ying Wang ${ }^{1,2,3,4,5}$, Nan $\mathrm{Lu}^{1,2,3,4,5}$, Yang Wei ${ }^{1,2,3,4,5}$, \\ Kehao Chen ${ }^{1,2,3,4,5}$ \\ ${ }^{1}$ Shaanxi Provincial Land Engineering Construction Group Co., Ltd. , Xi'an, China \\ ${ }^{2}$ Institute of Land Engineering and Technology, Shaanxi Provincial Land Engineering Construction \\ Group Co., Ltd., Xi'an, China \\ ${ }^{3}$ Key Laboratory of Degraded and Unused Land Consolidation Engineering, the Ministry of Natural \\ Resources, Xi'an, China \\ ${ }^{4}$ Shaanxi Provincial Land Consolidation Engineering Technology Research Center, Xi'an, China \\ ${ }^{5}$ Shaanxi Key Laboratory of Land Consolidation. Xi'an, China
}

\begin{abstract}
In order to understand the soil $\mathrm{pH}$ and main nutrient characteristics of newly added cultivated land in the eastern part of Guanzhong, and 160 soil samples were collected in 2016, the soil $\mathrm{pH}$, organic matter, total nitrogen, available phosphorus and available potassium in Heyang County were studied The suitability distribution of the indicators, using stepwise regression and path analysis methods, analyzes the direct relationship between soil $\mathrm{pH}$ and soil nutrients, and provides a theoretical basis for improving the newly added cultivated land. The results showed that the soil $\mathrm{pH}$ in Heyang County varied from 8.42 to 9.67, the soil organic matter content varied from 3.46 to $17.93 \mathrm{~g} / \mathrm{kg}$, the soil total nitrogen content varied from 0.13 to $5.61 \mathrm{~g} / \mathrm{kg}$, and the soil available phosphorus changed The range is $1.73 \sim 63.06 \mathrm{mg} / \mathrm{kg}$, and the soil available potassium range is $46.50 \sim 523.74$. The newly added soil has a certain nutrient basis, but it should be further adjusted and improved during the cultivation process. The direct positive effect on soil $\mathrm{pH}$ value is mainly soil organic matter, and the direct negative effect is mainly soil available phosphorus. By adjusting the organic matter, total nitrogen, available phosphorus and available potassium in the soil, the $\mathrm{pH}$ value of the soil can be effectively improved, so that the newly cultivated soil is suitable for the growth of local crops.
\end{abstract}

Keywords: Soil pH, Nutrient Characteristics, Land

\section{Introduction}

Soil nutrient status is the basic element that determines soil fertility, and is closely related to the growth status and quality of agricultural products [1,2]. With the continuous increase of China's economic volume, the demand for soil is becoming more and more urgent. Land engineering is to use engineering means to solve land problems, turn unused land into usable land or efficiently use the used land, which can actively coordinate the relationship 
between people and land. The process of harmonious development [3]. Among them, land remediation is one of the main ways to obtain new cultivated land. However, at present, people's research on soil nutrients mainly focuses on the land that has been cultivated for many years, and there is little research on the soil nutrients of newly added cultivated land. The soil $\mathrm{pH}$ is determined by the ratio of free $\mathrm{H}+$ and $\mathrm{OH}$ - ions in the soil. The $\mathrm{pH}$ directly affects the physical and chemical properties of the soil by affecting the formation, conversion and effectiveness of soil nutrients [4,5], which ultimately affects the yield and output of agricultural products quality. Therefore, studying the soil $\mathrm{pH}$ and nutrient characteristics of newly added cultivated land is of great reference significance for the management of newly added cultivated land and soil maintenance.

\section{Materials and methods}

\subsection{Overview of the study area}

Heyang County is located in the northeast of Guanzhong Plain in Shaanxi Province, in the east of Weibei Dry Highland, in the middle and east of Weinan City (longitude $109^{\circ} 58^{\prime}$ $110^{\circ} 25^{\prime}$ east, latitude $34^{\circ} 59^{\prime} \sim 35^{\circ} 26^{\prime}$ ), east of the Yellow River, and Linyi County in Shaanxi Province is separated; Dayu River is in the west and is adjacent to Chengcheng County; Yiliang Mountain is in the north, bordering Hancheng City and Huanglong County; Tiekila Mountain is in the south, and Dali County and Chengcheng County are connected (Study on the spatial and temporal evolution of land use in the county area). The average elevation of the study area is $721 \mathrm{~m}$, which is a warm temperate semi-humid monsoon climate. The distribution of rainfall is uneven, mainly concentrated from July to September, the rainfall is $553 \mathrm{~mm}$, the average annual temperature is $11.5{ }^{\circ} \mathrm{C}$, the temperature difference between day and night is large, and the entire county is stepped The topography gradually increased from southeast to northwest, with an altitude from $335 \mathrm{~m}$ to $1543 \mathrm{~m}$, a large drop, $41.8 \mathrm{~km}$ in length from north to south, $35.6 \mathrm{~km}$ in width from east to west, and a total area of $1328.71 \mathrm{~km} 2$. The landform types were river terraces, loess terraces, and low and middle mountains in sequence.

\subsection{Sample collection}

The soil samples used in the study were all collected after the land consolidation was completed. The survey was conducted in 12 towns and villages in Heyang County. They were divided into four types according to the terrain location. Five points were sampled according to the principles of "random", "equal volume" and "multipoint mixing" [6], and surface $(0 \sim 30 \mathrm{~cm})$ soil samples were collected, each about $1000 \mathrm{~g}$.

\subsection{Analysis items and methods}

The soil is naturally dried in the laboratory and treated according to the conventional method. The total nitrogen is determined by the Kjeldahl method; the soil organic matter is determined by the potassium dichromate volume method; the available phosphorus is determined by sodium bicarbonate leaching-molybdenum anti-colorimetry Quick-acting potassium was leached by $\mathrm{NH}_{4} \mathrm{OAC}$ and flame photometric method was determined; the total salt was determined by residue drying-mass method; $\mathrm{pH}$ was measured by $\mathrm{pH}$ meter [7]. For specific operation methods, please refer to "Soil Agricultural Chemical Analysis Methods" [8]. 


\subsection{Soil pH and main nutrient suitability classification}

Referring to previous studies [9, 10] and the recommended soil fertility classification recommended by the second national soil survey, the soil $\mathrm{pH}$, organic matter, total nitrogen, available phosphorus, and available potassium were classified as extremely low, low, suitable, high, and extremely There are 5 grades higher, see Table 1. According to the ratio of each grade, the soil $\mathrm{pH}$ and main nutrient abundance of the newly added cultivated land are evaluated.

Table 1 Newly added cultivated land soil $\mathrm{pH}$ and main nutrient suitability levels

\begin{tabular}{|c|c|c|c|c|c|}
\hline Grade & $\mathrm{pH}$ & Organic matter $(\mathrm{g} / \mathrm{kg})$ & Total nitrogen $(\mathrm{g} / \mathrm{kg})$ & Available phosphorus $(\mathrm{mg} / \mathrm{kg})$ & $\begin{array}{c}\text { Quick-acting } \\
\text { potassium }(\mathrm{mg} / \mathrm{kg})\end{array}$ \\
\hline Lowest & $<5.0$ & $<10$ & $<0.7$ & $<5$ & $<80$ \\
\hline Low & $5.0 \sim 5.5$ & $10 \sim 20$ & $0.7 \sim 1$ & $5 \sim 10$ & $80 \sim 160$ \\
\hline Suitable & $5.5 \sim 7.0$ & $20 \sim 30$ & $1 \sim 1.5$ & $10 \sim 30$ & $160 \sim 240$ \\
\hline High & $7.0 \sim 7.5$ & $30 \sim 40$ & $1.5 \sim 2.0$ & $30 \sim 40$ & $240 \sim 350$ \\
\hline Highest & $>7.5$ & $>40$ & $>2.0$ & $>40$ & $>350$ \\
\hline
\end{tabular}

\subsection{Data statistics and analysis}

Excel is used for data entry, sorting and drawing; SPSS.16 is used for statistical analysis, and LSD method is used for multiple comparisons.

\section{Results and analysis}

\subsection{Newly cultivated land soil pH and main nutrient characteristics}

It can be seen from Table 2 that the soil $\mathrm{pH}$ in Heyang County varies from 8.42 to 9.67, with an average value of 8.90 and a coefficient of variation of $3.04 \%$, which is a weak variation. From the perspective of sample distribution, $100 \%$ soil $\mathrm{pH}$ is distributed in a very high range Inside, it shows that the soil in Heyang County is generally alkaline, and corresponding measures need to be taken to adjust it.

The soil organic matter content varies from 3.46 to $17.93 \mathrm{~g} / \mathrm{kg}$, with an average value of $9.15 \mathrm{~g} / \mathrm{kg}$ and a coefficient of variation of $39.05 \%$, which is a medium variation. From the perspective of sample distribution, samples with soil organic matter content in the extremely low and low ranges It accounts for $64.10 \%$ and $35.90 \%$, and the soil organic matter content is relatively low, and measures need to be taken to adjust to increase the soil organic matter content of newly added cultivated land.

The total nitrogen content of soil in Heyang County varied from 0.13 to $5.61 \mathrm{~g} / \mathrm{kg}$, with an average value of $1.37 \mathrm{~g} / \mathrm{kg}$, which was within the appropriate range. From the point of view of sample distribution, the samples with soil total nitrogen content in the appropriate range accounted for $35.01 \%$, of which $<1 \mathrm{~g} / \mathrm{kg}$ samples accounted for $23.08 \%$, and samples with $>1.5 \mathrm{~g} / \mathrm{kg}$ accounted for $41.88 \%$, indicating that the total soil nitrogen content in Heyang County is generally On the high side, the total nitrogen content of most soils is suitable.

The increase of available phosphorus in the newly cultivated land in Heyang County ranges from 1.73 to $63.06 \mathrm{mg} / \mathrm{kg}$, and the coefficient of variation is $62.78 \%$, indicating that the available phosphorus content is unevenly distributed, and the average available phosphorus is $18.11 \mathrm{mg} / \mathrm{kg}$, which is within the appropriate range. From the point of view of sample distribution, the samples with soil available phosphorus content in the appropriate range accounted for $63.25 \%$, the samples with $<10 \mathrm{mg} / \mathrm{kg}$ accounted for 
$20.52 \%$, and the samples with $>30 \mathrm{mg} / \mathrm{kg}$ accounted for 16.24 .

The variation range of soil available potassium is $46.50 \sim 523.74$, which is similar to available phosphorus, and all belong to medium variation (variation coefficient $=62.24 \%$ ). The average value of soil available potassium is $158.67 \mathrm{mg} / \mathrm{kg}$ and the content of available potassium is slightly lower. From the perspective of sample distribution, the samples with available potassium in the appropriate range accounted for $17.95 \%$, of which samples with $<160 \mathrm{mg} / \mathrm{kg}$ accounted for $62.39 \%$, and samples with $>240 \mathrm{mg} / \mathrm{kg}$ accounted for 18.81 . Low.

Table 2 Soil $\mathrm{pH}$ and major nutrients in new arable land in Heyang County

\begin{tabular}{|c|c|c|c|c|c|c|c|c|}
\hline \multirow{2}{*}{ Index } & Mean \pm SD & Range & \multirow{2}{*}{ C.V.(\%) } & \multicolumn{5}{|c|}{ Suitability distribution frequency(\%) } \\
\cline { 5 - 10 } & & & Lowest & Low & Suitable & High & Highest \\
\hline $\mathrm{pH}$ & $8.90 \pm 0.27$ & $8.42 \sim 9.67$ & 3.04 & 0 & 0 & 0 & 0 & 100 \\
\hline Organic matter $(\mathrm{g} / \mathrm{kg})$ & $9.15 \pm 3.57$ & $3.46 \sim 17.93$ & 39.05 & 64.10 & 35.90 & 0 & 0 & 0 \\
\hline $\begin{array}{c}\text { Total nitrogen } \\
(\mathrm{g} / \mathrm{kg})\end{array}$ & $1.37 \pm 0.63$ & $0.13 \sim 5.61$ & 45.89 & 10.26 & 12.82 & 35.04 & 36.75 & 5.13 \\
\hline $\begin{array}{c}\text { Available } \\
\text { phosphorus(mg/kg) }\end{array}$ & $18.11 \pm 11.37$ & $1.73 \sim 63.06$ & 62.78 & 6.84 & 13.68 & 63.25 & 11.11 & 5.13 \\
\hline $\begin{array}{c}\text { Quick-acting potassium } \\
(\mathrm{mg} / \mathrm{kg})\end{array}$ & $158.67 \pm 98.76$ & $46.50 \sim 523.74$ & 62.24 & 17.09 & 45.30 & 17.95 & 11.97 & 6.84 \\
\hline
\end{tabular}

\subsection{Correlation of soil pH and soil nutrients in newly added cultivated Land}

The organic matter in the soil is the most important basic component in the soil, which not only determines the nutritional status of the soil, but also the organic matter in the soil can affect the mobility and bioavailability of the heavy metals in the soil by forming complexes with the heavy metal elements. Correlation analysis results show that there is a positive correlation between soil $\mathrm{pH}$ and soil organic matter in Heyang County $(\mathrm{R} 2=0.0982)$, the correlation coefficient is 4.0319 , the relationship between soil $\mathrm{pH}$ and organic matter is significant $(\mathrm{p}<0.05)$, indicating that the organic matter in the soil The $\mathrm{pH}$ content increases with the increase, which is contrary to the results of Wang Long et al. [11], mainly because Heyang County belongs to the northern region, the soil is overall alkaline, the soil has high calcium and magnesium plasma content, and Panzhihua belongs to the south In regions, the soil is more acidic.

Soil total nitrogen is an important indicator to measure soil fertility and the most intuitive indicator of soil fertility. It can be seen from Figure 2 that soil $\mathrm{pH}$ has a negative correlation with soil total nitrogen content $(\mathrm{R} 2=0.0095)$, the correlation coefficient is 0.1793 , and the correlation between the two is not significant ( $\mathrm{p}>0.05)$, indicating that soil $\mathrm{pH}$ and total nitrogen content The relationship is not particularly relevant, which is consistent with the results of Bai Junhong et al. [12], $\mathrm{pH}$ does not affect the change of soil total nitrogen content. .

Due to the overall alkaline soil in Heyang County, the phosphoric acid in the soil is difficult to absorb and fix the colloids such as $\mathrm{Fe}$ and Al, which makes the effective phosphorus content in the soil higher, which is beneficial to the growth of crops. However, the soil $\mathrm{pH}$ in Heyang County had a negative correlation with the available phosphorus content in the soil $(\mathrm{R} 2=0.2279)$, the correlation coefficient was -17.694 , and the correlation was extremely significant $(\mathrm{p}<0.01)$.

According to the correlation analysis, there is a positive correlation between soil $\mathrm{pH}$ and available potassium in the soil $(\mathrm{R} 2=0.063)$, the correlation coefficient is 73.012 , and the correlation between the two is significant $(\mathrm{p}<0.05)$. The content of available potassium in the soil increases with the increase of $\mathrm{pH}$, which is similar to the results of Deng Xiaohua et al.[13]. When the $\mathrm{pH}$ value increases, the adsorption of potassium by the soil increases, and 
the nitrogen and nitrogen in the fertilizer The utilization of phosphorus, potassium and other elements will also increase accordingly. Therefore, the available potassium utilization rate in the soil in this area is high, which is conducive to crop growth.

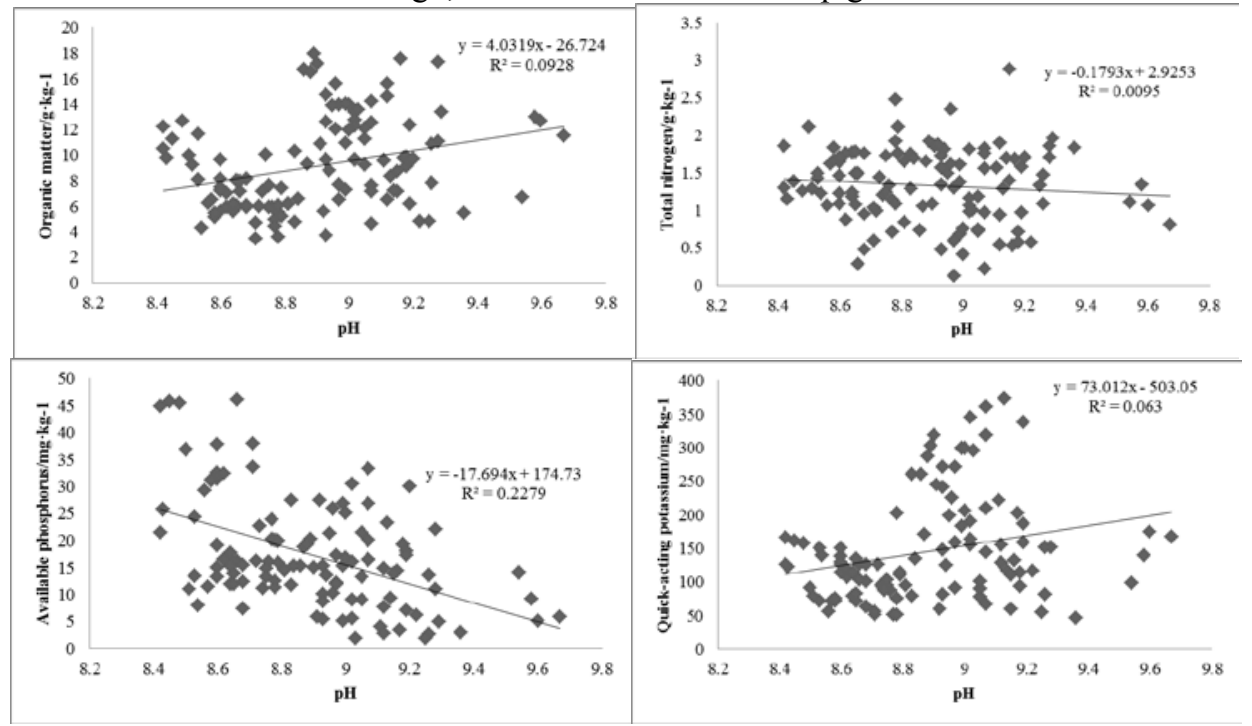

Fig. 1. Correlation analysis of soil $\mathrm{pH}$ and soil nutrients in newly added cultivated land

\section{Conclusion and discussion}

The soil $\mathrm{pH}$ in Heyang County varied from 8.42 to 9.67, with an average value of 8.90 , mainly represented by alkaline soil, and the variability between soil $\mathrm{pH}$ was small, indicating that the soil in this county is mainly alkaline soil, which is cultivated in cultivated land Need to pay attention to soil improvement, lower soil $\mathrm{pH}$. The content of soil organic matter varied from 3.46 to $17.93 \mathrm{~g} / \mathrm{kg}$, with an average value of $9.15 \mathrm{~g} / \mathrm{kg}$. The content of soil organic matter was low, and measures need to be taken to adjust to increase the content of soil organic matter in newly added cultivated land. The total nitrogen content of soil in Heyang County varied from 0.13 to $5.61 \mathrm{~g} / \mathrm{kg}$, with an average value of $1.37 \mathrm{~g} / \mathrm{kg}$, indicating that the total nitrogen content in Heyang County was generally high, and most of the soil was suitable. The change of available phosphorus in newly cultivated land in Heyang County was $1.73 \sim 63.06 \mathrm{mg} / \mathrm{kg}$, and the coefficient of variation was $62.78 \%$, indicating that the available phosphorus content was unevenly distributed, but in general, the available phosphorus content in newly cultivated land in Heyang County was generally appropriate. The range of soil available potassium ranged from 46.50 to 523.74 , all of which were moderately variable (coefficient of variation = $62.24 \%$ ). The average value of soil available potassium was $158.67 \mathrm{mg} / \mathrm{kg}$, and the content of available potassium was slightly lower. Therefore, for the newly added arable land in the county, the soil has a certain nutrient base, but the nutrient level should be further adjusted and increased during the planting process.

\section{Acknowledgments}

This work was financially supported by Research Project of Shaanxi Provincial Land Engineering Construction Group in China (DJNY2019-16 \& DJNY 2020-21) and the Fund Project of Shaanxi Key Laboratory of Land Consolidation (2019-JC05 \& 2018-JC17). 


\section{References}

1. Cao Zhihong. Soil and fertilization for high-quality flue-cured tobacco production [M]. Nanjing: Jiangsu Science and Technology Press, 1991: 38 - 43.

2. Zuo Xingjun, Xu Shujian. Soil nutrient status and tobacco leaf quality and relationship analysis in Linyi tobacco area [J]. China Tobacco Science, 2010, 31 (5): 49 - 52.

3. Han Jichang. Introduction to Land Engineering [M]. Science Press, 2013.

4. Zou Kai, Deng Xiaohua, Li Yongfu, et al. Temporal and spatial characteristics of $\mathrm{pH}$ in tobacco planting soil in Shaoyang and its relationship with soil nutrients [J]. Journal of Beijing Agricultural College, 2014, 29 (1): 6 - 9.

5. Hu Xiangdan, Deng Xiaohua, Wang Feng, et al. Distribution characteristics of tobacco planting soil $\mathrm{pH}$ in southwestern Guizhou and its relationship with soil nutrients $[\mathrm{J}]$. Journal of Anhui Agricultural University, 2014, 41 (6): 1070 - 1074.

6. Ministry of Agriculture of the People's Republic of China. Soil testing: People's Republic of China Agricultural Industry Standard NY / T 1121 [M]. Beijing: China Agricultural Press, 2007.

7. Meng Ke, Meng Xianxi, Shi Chongxiu. Research on the laboratory processing and preservation method of soil samples with mercury background value [J]. Journal of Agricultural Environmental Sciences, 1985 (04): 13-17.

8. Lu Rukun. Soil agricultural chemical analysis method [M]. Beijing: China Agricultural Science and Technology Press, 2000.

9. Chen Jianghua, Li Zhihong, Liu Jianli, et al. Evaluation of soil nutrient abundance in major tobacco regions in China [J]. Chinese Journal of Tobacco, 2004.11 (3): 14-18.

10. Luo Jianxin, Shi Lihong, Long Shiping. The status and evaluation of soil nutrients in the main tobacco producing areas of Hunan [J]. Journal of Hunan Agricultural University: Natural Science Edition, 2005, 31 (4): 376-380.

11. Wang Long, Ye Xiefeng, Zhang Mengchu, et al. Correlation and path analysis of soil $\mathrm{pH}$ value and soil nutrients [J]. Jiangsu Agricultural Sciences, 2013 (01): 371-372 + 398.

12. Bai Junhong, Deng Wei, Zhang Yuxia. The spatial differentiation law of soil organic matter and total nitrogen in the ring-shaped vegetation zone of Wulanpao wetland in Inner Mongolia [J]. Lake Science, 2002 (02): 51-57.

13. Deng Xiaohua, Zhang Yao, Tian Feng, et al. Tobacco planting soil $\mathrm{pH}$ and main nutrient characteristics and their interrelationship in western Hunan [J]. Soil, 2017, 049 (001): 49-56. 